\title{
Clinical outcomes of patients with Garden I updates and II femoral neck fractures as verified on MRI: a retrospective case series
}

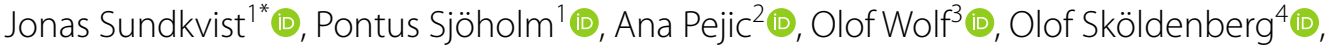 \\ Cecilia Rogmark ${ }^{2}$ and Sebastian Mukka ${ }^{1}$ (1)
}

\begin{abstract}
Background: Between 2 to 10\% of non-displaced femoral neck fractures (nFNF) cannot be diagnosed on plain radiographs and require further imaging investigation to be detected or verified. These fractures are referred to as occult hip fractures. This study aimed to report treatment failures, reoperations and mortality in a consecutive series of occult femoral neck fractures (FNF) treated with internal fixation (IF).

Methods: A retrospective multicenter study was performed based on a consecutive series of patients aged $\geq 60$ years with an occult magnetic resonance imaging (MRI) verified Garden I and II FNF sustained after a trauma and treated with primary IF. We included 93 patients with a minimum 2-year follow-up. Radiographic assessment encompassed pre- and postoperative tilt, implant inclination, MRI and treatment failure. Data on reoperation and mortality were collected. Treatment failure was defined as fixation failure, nonunion, avascular necrosis or posttraumatic osteoarthritis.
\end{abstract}

Results: The study comprised of 93 patients (72\% women, 67/93) with a mean age of 82 (range, 60-97) years. Overall, $6(6 \%)$ patients had major reoperations. 2 (2\%) had minor reoperations. One-month mortality was 7\%, 1-year mortality was 20\% and 2-year mortality was 31\%.

Conclusion: This multicenter cohort study identifies a subgroup of elderly patients with MRI verified Garden I and II FNFs sustained after trauma, i.e. occult fractures. These fractures seem to have a lower complication rate compared to nFNF identified on plain radiographs.

Level of evidence: Prognostic Level V. See Instructions to Authors for a complete description of levels of evidence.

\section{Background}

Femoral neck fractures (FNFs) are commonly encountered in orthopedic practice and the absolute numbers are expected to increase further as there is a growing elderly population worldwide [1]. Most FNFs can receive adequate treatment after being diagnosed with plain radiographs [2]. A small group of non-displaced (nFNF) or

*Correspondence: Jonas.sundkvist@umu.se

1 Department of Surgical and Perioperative Sciences, Orthopedics, Umeå University, Umeå, Sweden

Full list of author information is available at the end of the article minimally displaced FNFs sustained after trauma cannot be diagnosed on plain radiographs and require further investigation with computed tomography $(\mathrm{CT})$, radionuclide bone scan or magnetic resonance imaging (MRI). These fractures are referred to as occult hip fractures and represent $2-10 \%$ of all nFNF [2-6]. MRI is more accurate than both $\mathrm{CT}$ and radionuclide bone scans to detect occult fractures and also reduce time to diagnosis $[2,7$, 8]. Reoperation rates after internal fixation (IF) of nFNFs detected on plain radiographs range from 8 to $19 \%$ in previous reports [9]. However, there may be subgroups of original author(s) and the source, provide a link to the Creative Commons licence, and indicate if changes were made. The images or other third party material in this article are included in the article's Creative Commons licence, unless indicated otherwise in a credit line to the material. If material is not included in the article's Creative Commons licence and your intended use is not permitted by statutory regulation or exceeds the permitted use, you will need to obtain permission directly from the copyright holder. To view a copy of this licence, visit http://creativecommons.org/licenses/by/4.0/. The Creative Commons Public Domain Dedication waiver (http://creativeco mmons.org/publicdomain/zero/1.0/) applies to the data made available in this article, unless otherwise stated in a credit line to the data. 
nFNFs whose fracture characteristics may lead to different outcomes, complications and reoperation rates $[10$, 11]. The MRI verified nFNFs, i.e. the occult hip fractures, is a potential subgroup. There are few reports on the outcome of these fractures [12, 13]. Therefore, our study aimed to describe treatment failures and reoperations in patients with MRI verified FNFs treated with IF.

\section{Method}

\section{Study settings}

A retrospective multicenter cohort study was performed including patients $\geq 60$ years with an MRI verified FNF treated with IF between January 2003 and October 2018 at four orthopedic departments in Sweden: Umeå University Hospital (2003-2018) a third-level university hospital with a catchment area of about 160,000 inhabitants, Danderyd Hospital (2010-2018) a third-level university hospital with a catchment area of about 500,000 inhabitants, Skåne University Hospital in Malmö (2005-2014) a third-level university hospital with a catchment area of about 450,000 inhabitants and Skellefteå Hospital (20042018) a first-level hospital with a catchment area of about 80,000 inhabitants.

\section{Patients and data collection}

A consecutive series of patients $\geq 60$ years with an MRI verified FNF were included. Only patients treated with IF by either cannulated screws or pins were included and followed until death or December 2020. Patient demographics were collected by a review of the surgical and medical charts. We collected data including age, sex, ASA classification, cognitive impairment (diagnosis in medical records prior to fracture), use of a walking aid prior to fracture, admission from sheltered housing or a nursing home, the use of MRI for diagnosis, method of surgical treatment, reoperation, treatment failure and date of death.

\section{Radiographic assessment}

The plain anteroposterior (AP) radiographs were used to classify fractures according to the Garden classification system (Fig. $1 \mathrm{a}, \mathrm{b}$ ) [14]. The pre- and postoperative tilt of the femoral head was measured on a lateral radiograph of the hip using the method described by Palm et al. [10, $11,15]$. If a postoperative lateral radiograph was missing, the postoperative tilt was measured on the intraoperative image documentation. For implant inclination we performed measurements on the inferior pin or screw on the postoperative AP radiograph [16]. Three raters (JS, PS, AP), who were not blinded, performed all measurements. At the time of the study no national guidelines on diagnosing fractures with MRI were present, however, in most cases T1, T2 and STIR weighted sequences were

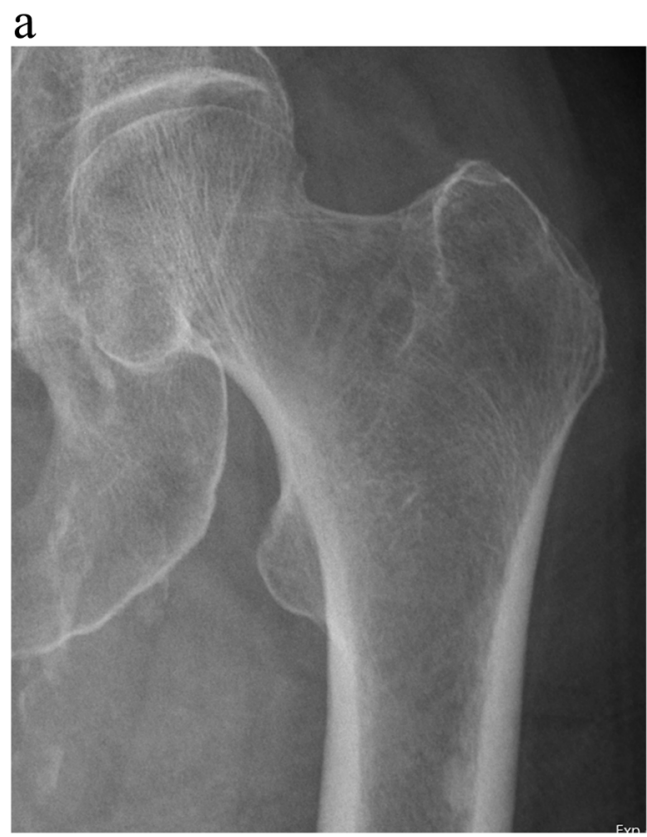

b

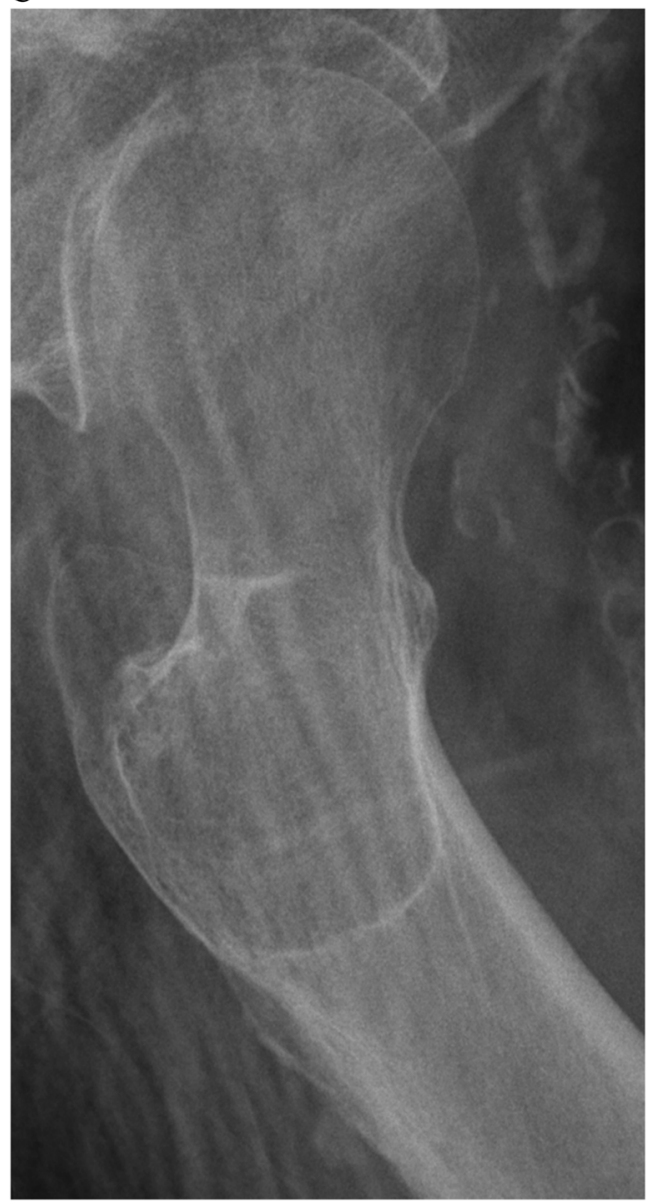

Fig. 1 Plain radiographs of an occult femoral neck fracture. a) AP projection of the hip. b) lateral projection of the hip 
used (Fig. 2a, b). All images were digitally acquired using a Picture Archiving and Communication System (PACS, Impax, Agfa, Antwerp, Belgium).

\section{Internal fixation}

IF was performed according to the same principles at the 4 hospitals. With the patient on a fracture table and under intra operative imaging 2 or 3 pins/screws were placed along the femoral neck transfixing the fracture. Either Hansson Pins; Swemac Orthopaedics AB, Sweden or Olmed Screws; DePuy/Johnson \& Johnson, Sollentuna, Sweden were used.

\section{Outcome measurements}

The primary end-point was a major reoperation due to avascular necrosis (AVN), fixation failure, posttraumatic osteoarthritis or nonunion. Major reoperation was defined as hip arthroplasty, excision arthroplasty or reosteosynthesis due to peri-implant fractures. The definition of minor reoperation was removal or adjustment of implant.

\section{Statistical analysis}

Variables are presented as proportions of all fractures. Nominal variables are presented as proportions of all fractures and scale variables as means \pm standard deviation $( \pm S D)$ and range. We used SPSS (IBM SPSS Statistics for Mac, Version 26.0, Armonk, NY: IBM Corp. USA) for statistical analyses.

\section{Results}

\section{Patients and descriptive data}

We included 93 patients (72\% females) with a mean age of 82 (range, 60-97) (Table 1). The median follow-up was 74 (range, 0-190) months. One-third of the patients suffered from cognitive impairment and $23 \%$ were admitted from sheltered housing. The 30-day mortality was $7 \%$, 1 -year mortality was $20 \%$ and 2-year mortality was $31 \%$.

\section{Radiographic assessment}

We found all of the included fractures to be non-displaced on the AP radiograph and used the method described by Palm et al. [15] to verify that the fractures were non-displaced or minimally displaced on the lateral radiograph (Table 2 ).

\section{Treatment failure and reoperations}

Overall, $6(6 \%)$ patients were classified as treatment failure and were treated with reoperations (Fig. 3). In total, 8 (8\%) patients had reoperation as two patients had implant removal (Table 3). 1 patient with AVN, 1 with non-union, 2 suffered fixation failure and 1 a peri-implant fracture. 1 developed post-traumatic osteoarthritis. $8(8 \%)$ patients

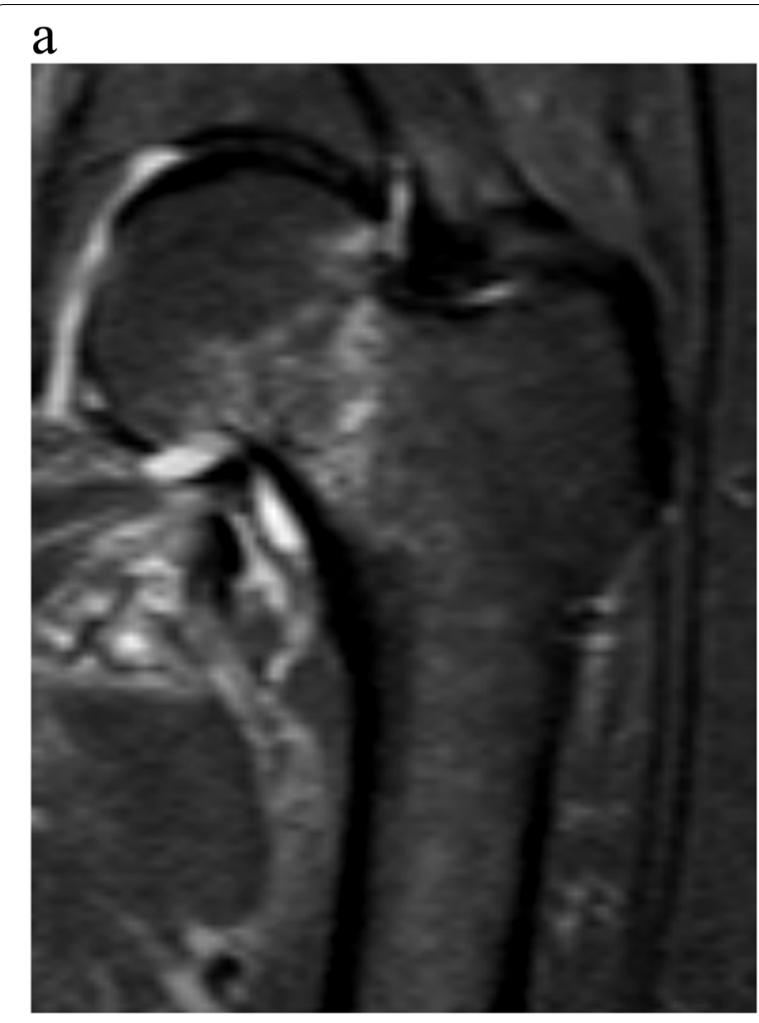

b

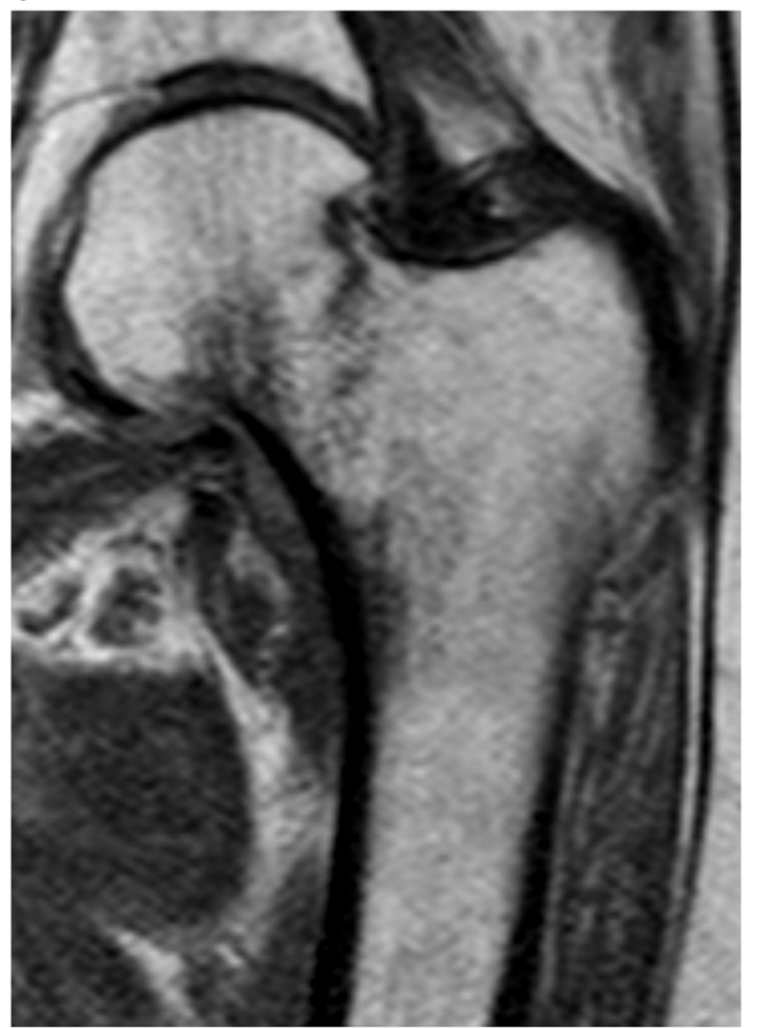

Fig. $2 \mathrm{MRI}$ of the same occult femoral neck fracture. a) T2 weighted anteroposterior image. b) T1 weighted anteroposterior image 
Table 1 Patient characteristics: Distribution of sex, age at injury, cognitive impairment and sheltered housing

\begin{tabular}{ll}
\hline $\begin{array}{l}\text { Patient characteristics }(\boldsymbol{n}=\mathbf{9 3}) \text { : Data are presented as median and } \\
\text { range or the number of the patients with percent in parentheses }\end{array}$ \\
\hline Age & $84(60-97)$ \\
Women & $67(72 \%)$ \\
ASA classification & \\
$1-2$ & $26(28 \%)$ \\
$3-5$ & $63(68 \%)$ \\
Missing & $4(4 \%)$ \\
Cognitive impairment & $31(33 \%)$ \\
Sheltered housing & $21(23 \%)$
\end{tabular}

$\mathrm{ASA}=$ American Society of Anesthesiologist

Table 2 Fracture characteristics: Degree of dorsal tilt preoperative and postoperative and implant inclination

\begin{tabular}{ll}
\hline $\begin{array}{l}\text { Patient characteristics }(\boldsymbol{n}=\mathbf{9 3}) \text { : Values are given as median and } \\
\text { interquartile range }\end{array}$ \\
\hline Preoperative tilt & $4^{\circ}(7)$ \\
Preoperative tilt & $3^{\circ}(7)$ \\
Implant Inclination & $135^{\circ}(11)$ \\
$\leq 125^{\circ \dagger}$ & $7(8 \%)$ \\
$>125^{\circ}$ & $86(92 \%)$
\end{tabular}

${ }^{\dagger}$ The values represent the number of the patients and percent in the parentheses

underwent a reoperation, including minor procedures during the study period. 6 patients had a major reoperation during the first 2 years after IF, 2 patients received a total hip arthroplasty, 2 patients hemiarthroplasty and 2 patients underwent re-osteosynthesis. Minor reoperation with removal of implants was performed in 2 patients.

\section{Discussion}

The main finding in this study is that MRI verified nFNFs, i.e. occult hip fractures, have a low but not insignificant rate of complications and reoperations when compared to nFNFs verified with plain radiographs [9]. In the present study the complication rate was $6 \%$, major reoperations were evenly distributed between $\mathrm{AVN}$, fixation failure, peri-implant fractures and post-traumatic arthritis resulting in 2 cases of re-osteosynthesis and 4 cases of hip arthroplasty. 2 patients had minor reoperation defined as implant removal. It has previously been reported that nFNFs treated with IF have reoperation rates between 8 and 19\% [9]. These reoperation rates are higher than those presented in our cohort due to our selection of patients. We suggest that the MRI verified occult fracture may be a subgroup of nFNF with a relatively low rate of reoperations following IF. Other

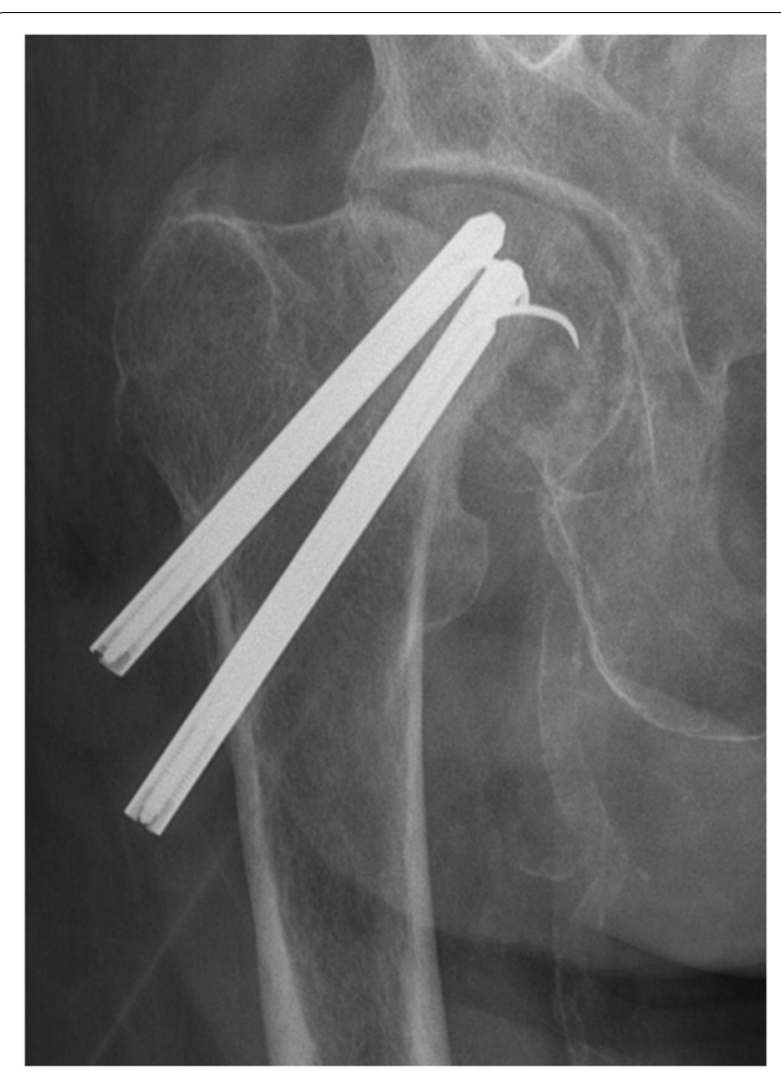

Fig. 3 Plain radiographs of an occult femoral neck fracture treated with internal fixation and who later developed a treatment failure

Table 3 Treatment failure and reoperations

Treatment failure and reoperation $(n=8)$ : Values are given as median and range or the number of the patients with percent in parentheses

\begin{tabular}{ll}
\hline Age & $83(60-92)$ \\
Female & $5(63 \%)$ \\
Treatment failure & $6(6 \%)$ \\
Avascular necrosis (AVN) & 1 \\
Non-union & 1 \\
Fixation failure & 2 \\
Post-traumatic arthritis & 1 \\
Peri-implant fracture & 1 \\
Reoperation & $8(9 \%)$ \\
Total arthroplasty & 2 \\
Removal of osteosynthesis & 2 \\
Hemiarthoplasty & 2 \\
Re-osteosynthesis & 2 \\
\hline
\end{tabular}

subgroups of nFNFs treated with IF have been identified with significant reoperation rates. A preoperative posterior tilt over $20^{\circ}$ on the lateral radiograph has been shown 
to increase the risk of treatment failure and major reoperation $[17-20]$. An anterior tilt of at least $10^{\circ}$ is associated with up to $40 \%$ suffering a treatment failure $[10,11]$. However, these reoperation rates in combination with the limited literature comparing IF with hip arthroplasty in the elderly population, warrant further comparative studies [21, 22]. Limitations of the present study include the retrospective design. In addition, the limited sample size which prevents us from performing any in-depth analysis of risk factors associated with treatment failure and reoperations. We did not perform any intra- or interobserver reliability testing of the obtained measurements. However, interobserver reliability has been presented in a previous study from our institution [11]. Nevertheless, this is, to our knowledge, the largest consecutive series of MRI verified nFNFs presented to date. The sample size included offers a rough model of the outcome of these fractures which represents the"best possible" clinical results of a FNF treated with IF. We believe our data is highly reliable, as we used the unique Swedish personal identity number to collect data by reviewing the hospital records of all contributing departments. In addition, the hospitals provide all acute orthopaedic care in the catchment area to ensure completeness of data. However, this fragile group of patients, with a relatively large share living in sheltered housing, are often unfit to seek healthcare services actively. This could mask the identification of failures and potential major reoperations related to nFNF.

\section{Conclusion}

Based on our results, MRI verified nFNFs have a lower reoperation rate than $\mathrm{nFNF}$ seen on conventional radiographs. Still, MRI verified nFNF are not exempt from hip related complications and clinicians and patients need to be aware that even these perceived benign fractures are at risk of reoperation.

\section{Abbreviations \\ NFNF: Non-displaced femoral neck fracture; FNF: Femoral neck fracture; IF: Internal fixation; MRI: Magnetic resonance imaging; CT: Computed tomog- raphy; RCT: Randomized clinical trial; ASA: American Society of Anesthesi- ologists; AP: Anteroposterior; PACS: Picture Archiving and Communication System; SPSS: Statistical Package for the Social Sciences.}

\section{Acknowledgements \\ None}

\section{Authors' contributions}

JS collected data, performed radiographic measurements, performed statistical analysis and wrote the manuscript. PS, AP performed radiographic measurements, reviewed the manuscript. OW, OS wrote and reviewed the manuscript. CR initiated the study, wrote and reviewed the manuscript. SM initiated the study, supervised JS, performed statistical analysis and wrote and reviewed the manuscript. All authors have read and approved the final manuscript.

\section{Funding}

Open access funding provided by Umea University. The study was funded by grants from the regional agreement on medical training and clinical research (ALF) between Västerbotten County Council and Umeå University, and between Skane Region and Lund University.

\section{Availability of data and materials}

Due to Swedish legislation, the datasets used and/or analyzed during the current study are not publicly available. Data is available from the corresponding author on reasonable request.

\section{Declarations}

\section{Ethics approval and consent to participate}

The study was conducted according to the principles of the Helsinki Declaration and was approved by the Swedish Ethical Review Authority (entry number 2019-06449) and the regional ethical committee in Lund, Sweden (EPN 2015/91). The consent to participate was waived by the Swedish Ethical Review Authority due to the retrospective design of the study.

\section{Consent for publication}

Not applicable

\section{Competing interests}

The authors declare no competing interests.

\section{Author details}

${ }^{1}$ Department of Surgical and Perioperative Sciences, Orthopedics, Umeå University, Umeå, Sweden. ${ }^{2}$ Department of Orthopaedics, Lund University, Skåne University Hospital, Malmö, Sweden. ${ }^{3}$ Department of Surgical Sciences, Orthopaedics, Uppsala University, Uppsala, Sweden. ${ }^{4}$ Karolinska Institutet, Department of Clinical Sciences at Danderyd Hospital, Unit of Orthopaedics, Stockholm, Sweden.

Received: 29 August 2021 Accepted: 3 February 2022

Published online: 12 February 2022

\section{References}

1. Chen IJ, Chiang CY, Li YH, Chang CH, Hu CC, Chen DW, Chang Y, Yang WE, Shih HN, Ueng SW, Hsieh PH. Nationwide cohort study of hip fractures: time trends in the incidence rates and projections up to 2035. Osteoporos Int. 2015;26(2):681-8. https://doi.org/10.1007/s00198-014-2930-z Epub 2014 Oct 30.

2. Lubovsky O, Liebergall M, Mattan Y, Weil Y, Mosheiff R. Early diagnosis of occult hip fractures MRI versus CT scan. Injury 2005;36(6):788-92)

3. Parker MJ. Missed hip fractures. Arch Emerg Med. 1992;9(1):23-7.

4. Gill SK, Smith J, Fox R, Chesser TJ. Investigation of occult hip fractures: the use of CT and MRI. ScientificWorldJournal. 2013;2013:830319.

5. Hossain M, Barwick C, Sinha AK, Andrew JG. Is magnetic resonance imaging (MRI) necessary to exclude occult hip fracture? Injury. 2007;38(10):1204-8.

6. Frihagen F, Nordsletten L, Tariq R, Madsen JE. MRI diagnosis of occult hip fractures. Acta Orthop. 2005;76(4):524-30.

7. Verbeeten $\mathrm{KM}$, Hermann $\mathrm{KL}$, Hasselqvist M, Lausten GS, Joergensen $P$, Jensen CM, et al. The advantages of MRI in the detection of occult hip fractures. Eur Radiol. 2005;15(1):165-9.

8. Haubro M, Stougaard C, Torfing T, Overgaard S. Sensitivity and specificity of CT- and MRI-scanning in evaluation of occult fracture of the proximal femur. Injury. 2015;46(8):1557-61.

9. Onativia IJ, Slullitel PA, Dilernia FD, Viezcas JMG, Vietto V, Ramkumar PN, Buttaro MA, Piuzzi NS. Outcomes of nondisplaced intracapsular femoral neck fractures with internal screw fixation in elderly patients: a systematic review. Hip Int. 2018;28(1):18-28.

10. Sjöholm P, Otten V, Wolf O, Gordon M, Karsten G, Sköldenberg O, Mukka S Posterior and anterior tilt increases the risk of failure after internal fixation of Garden I and II femoral neck fracture. Acta Orthop. 2019;90(6):537-41. https://doi.org/10.1080/17453674.2019.1637469. 
11. Sjöholm P, Sundkvist J, Wolf O, Sköldenberg O, Gordon M, Mukka S. Preoperative Anterior and Posterior Tilt of Garden I-II Femoral Neck Fractures Predict Treatment Failure and Need for Reoperation in Patients Over 60 Years. JB JS Open Access. 2021 Oct 28;6(4):e21.00045. doi: https://doi.org/ 10.2106/JBJS.OA.21.00045.

12. Pejic A, Hansson S, Rogmark C. Magnetic resonance imaging for verifying hip fracture diagnosis why, when and how? Injury. 2017;48(3):687-91. https://doi.org/10.1016/j.injury.2017.01.025 Epub 2017 Jan 17.

13. Beloosesky Y, Hershkovitz A, Guz A, Golan H, Salai M, Weiss A. Clinical characteristics and long-term mortality of occult hip fracture elderly patients. Injury. 2010;41(4):343-7. https://doi.org/10.1016/j.injury.2009.08. 017.

14. Garden RS. Low-angle fixation in fractures of the femoral neck. J Bone Joint Surg Br. 1961;43:647-63.

15. Palm H, Gosvig K, Krasheninnikoff M, Jacobsen S, Gebuhr P. A new measurement for posterior tilt predicts reoperation in undisplaced femoral neck fractures: 113 consecutive patients treated by internal fixation and followed for 1 year. Acta Orthop. 2009;80(3):303-7.

16. Nyholm AM, Palm H, Sandholdt H, Troelsen A, Gromov K; Danish Fracture Database Collaborators. Osteosynthesis with Parallel Implants in the Treatment of Femoral Neck Fractures: Minimal Effect of Implant Position on Risk of Reoperation. J Bone Joint Surg Am. 2018 Oct 3;100(19):16821690. doi: https://doi.org/10.2106/JBJS.18.00270.

17. Nielsen LL, Smidt NS, Erichsen JL, Palm H, Viberg B. Posterior tilt in nondisplaced femoral neck fractures increases the risk of reoperations after osteosynthesis. A systematic review and meta-analysis Injury. 2020;51(12):2771-8. https://doi.org/10.1016/j.injury.2020.09.033.

18. Dolatowski FC, Adampour M, Frihagen F, Stavem K, Erik Utvåg S, Hoelsbrekken SE. Preoperative posterior tilt of at least $20^{\circ}$ increased the risk of fixation failure in Garden-I and -II femoral neck fractures. Acta Orthop. 2016;87(3):252-6.

19. Okike K, Udogwu UN, Isaac M, Sprague S, Swiontkowski MF, Bhandari M, Slobogean GP, FAITH Investigators. Not All Garden-I and II Femoral Neck Fractures in the Elderly Should Be Fixed: Effect of Posterior Tilt on Rates of Subsequent Arthroplasty. J Bone Joint Surg Am. 2019 Oct 16;101 (20):1852-1859. doi: https://doi.org/10.2106/JBJS.18.01256

20. Honkanen JS, Ekman EM, Huovinen VK, Mäkelä KT, Koivisto M, Karvonen MP, Laaksonen I. Preoperative Posterior Tilt Increases the Risk of Later Conversion to Arthroplasty After Osteosynthesis for Femoral Neck Fracture. J Arthroplasty. 2021 May 5:S0883-5403(21)00411-3. doi: https://doi. org/10.1016/j.arth.2021.04.039. Epub ahead of print

21. Wolf O, Sjöholm P, Hailer NP, Möller M, Mukka S. Study protocol: HipSTHeR - a register-based randomised controlled trial - hip screws or (total) hip replacement for undisplaced femoral neck fractures in older patients. BMC Geriatr. 2020;20(1):19. https://doi.org/10.1186/s12877-020-1418-2.

22. Viberg B, Kold S, Brink O, Larsen MS, Hare KB, Palm H; SENSE collaborators. Is arthroplaSty bEtter than interNal fixation for undiSplaced femoral nEck fracture? A national pragmatic RCT: the SENSE trial. BMJ Open. 2020 Oct 10;10(10):e038442. doi: https://doi.org/10.1136/bmjopen-2020-038442

\section{Publisher's Note}

Springer Nature remains neutral with regard to jurisdictional claims in published maps and institutional affiliations.

Ready to submit your research? Choose BMC and benefit from:

- fast, convenient online submission

- thorough peer review by experienced researchers in your field

- rapid publication on acceptance

- support for research data, including large and complex data types

- gold Open Access which fosters wider collaboration and increased citations

- maximum visibility for your research: over 100M website views per year

At BMC, research is always in progress.

Learn more biomedcentral.com/submissions 